\title{
Factors associated with Salmonella infection in patients with gastrointestinal complaints seeking health care at Regional Hospital in Southern Highland of Tanzania
}

Fadhili A. Ngogo ${ }^{1,2+}$, Agricola Joachim ${ }^{1}$, Ahmed M. Abade², Susan F. Rumisha ${ }^{3}$, Mucho M. Mizinduko ${ }^{1}$ and Mtebe V. Majigo ${ }^{1 *+}$ (D)

\begin{abstract}
Background: Salmonellosis remains an important public health problem globally. The disease is among the leading causes of morbidity and mortality in developing countries that experience poor hygiene and lack of access to clean and safe water. There was an increase in reported cases of Salmonellosis in Njombe Region, Southern Highland of Tanzania between 2015 and 2016 based on clinical diagnosis. Nevertheless, little is known about the factors contributing to the transmission of this disease in the region. This study was conducted to determine the prevalence, antimicrobial susceptibility, and factors associated with Salmonella infection among patients who report gastrointestinal complaints.

Methods: A cross-sectional study was conducted from December 2017 to February 2018 among patients with gastrointestinal complaints at Kibena Regional Hospital. Stool samples were submitted for isolation of Salmonella spp. Identification was based on conventional biochemical tests and serotyping to differentiate typhoid and nontyphoid Salmonella (NTS). Antimicrobial susceptibility was performed using the Kirby-Bauer disc diffusion method. Multivariable logistic regression analysis was performed to examine the factors independently associated with Salmonella infection.

Results: The prevalence of Salmonella infection among participants with gastrointestinal complaints was 16.5\% (95\% Cl: 12.7-21.1) of them, 83.7, 95\% Cl: 70.9-91.5 were NTS while 16.3, 95\% Cl: 8.5-29.0 were Typhoid Salmonella species.

All isolates were sensitive to ceftriaxone and ciprofloxacin, whereas 27.8 and 100\% were resistant to co-trimoxazole and ampicillin respectively. The odd of Salmonella infection was fourfold higher among participants with formal employment (AOR 3.8, 95\% Cl, 1.53-9.40). Use of water from wells/rivers (AOR 2.2, 95\% Cl, 1.07-4.45), drinking untreated water (AOR 2.6, 95\% Cl, 1.21-5.48) and often eating at a restaurant (AOR 3.4, 95\% Cl, 1.28-8.93) had increased odds of Salmonella infection. Likewise, having abdominal pain (AOR 8.5, 95\% Cl, 1.81-39.78) and diarrhea (AOR 2.3, 95\% Cl, 1.12-4.68) were independent symptoms that predict Salmonella infection.

Conclusion: There is a high prevalence of Salmonella infection among people who report gastrointestinal complaints and it is clinically predicated by diarhoea and abdominal pain. Employed participants and those eating at restaurant and drinking unsafe water had higher risk of infection. Salmonella spp. causing gastroenteritis has developed resistance to commonly used antibiotics.
\end{abstract}

Keywords: Salmonella infection, Salmonellosis, Gastroenteritis, Antimicrobial resistance, Tanzania

\footnotetext{
* Correspondence: mmajigo@gmail.com

${ }^{+}$Fadhili A. Ngogo and Mtebe V. Majigo contributed equally to this work.

${ }^{1}$ Muhimbili University of Health and Allied Sciences, Dar es Salaam, Tanzania

Full list of author information is available at the end of the article
}

(c) The Author(s). 2020 Open Access This article is distributed under the terms of the Creative Commons Attribution 4.0 International License (http://creativecommons.org/licenses/by/4.0/), which permits unrestricted use, distribution, and reproduction in any medium, provided you give appropriate credit to the original author(s) and the source, provide a link to the Creative Commons license, and indicate if changes were made. The Creative Commons Public Domain Dedication waiver (http://creativecommons.org/publicdomain/zero/1.0/) applies to the data made available in this article, unless otherwise stated. 


\section{Introduction}

Salmonella infection remains a major public health concern worldwide [1], gastroenteritis being the most common manifestation [2]. Salmonella serovars causing illness in humans are grouped into two, Salmonella enterica serovars referred to as typhoidal Salmonella and other serovars grouped as non-typhoidal Salmonella (NTS). The NTS is more often the cause of gastroenteritis, an invasive disease frequently occurring in developing countries $[3,4]$.

Salmonella is among common food-borne pathogens predominantly found in poultry, eggs, dairy products, and vegetables, acquired directly or indirectly from human or animal excreta $[1,5,6]$. The risk for infection is high in low-income countries due to poor hygiene and lack of access to safe water and food $[3,6,7]$. The NTS infection, accounts for 93.8 million cases of gastroenteritis and 155 thousand deaths per annum globally [2]. Studies conducted in Tanzania among patients with febrile illnesses revealed that Salmonella spp. is among the predominant isolate causing either bacteremia or gastroenteritis $[8,9]$.

The Tanzania Health Management Information System data of 2016 reported 12,055 cases of salmonellosis in the Njombe region. The reported cases were based on clinical diagnosis due to limited laboratory services. Furthermore, resistance to a commonly used antibiotic in our setting for the treatment of Salmonella infection has been reported $[4,10,11]$. In line with the inadequacy of laboratory services, the true magnitude of Salmonella infection among patients with gastrointestinal symptoms is not known. Likewise, information on the factors contributing to Salmonella infection in the region is limited. This cross-sectional study estimated the prevalence of Salmonella infection using culture and identified factors contributing for the transmission of the infection. The finding from this study may assist in setting appropriate measures for the prevention and control of salmonellosis.

\section{Methods}

\section{Study design, setting and population}

This was a cross-sectional study approved by the institutional review board of Muhimbili University of Health and Allied Sciences Ref: MU/PGS/SAEC/Vol.X on 1st Nov 2017. The study was conducted between December 2017 and February 2018 at Kibena Regional Hospital located in the Njombe region, Southern Highland zone of Tanzania. Geographically the hospital is located at latitudes $-9^{\circ} 3085^{\prime}$ and the longitude $34^{\circ} 7716^{\prime}$. The hospital bed capacity is 160; attend approximately 860 outpatients and 240 in-patients monthly. Gastrointestinal Diseases are among the top 10 diseases at Kibena regional hospital.
The study population was patients seeking medical care at the hospital and clinically suspected with gastrointestinal disease. Patients with variable severity of nonbloody diarrhea, abdominal pain, nausea or vomiting were requested to participate. Only clients whom either self, parents or guardians provided written informed consent to participate were enrolled.

\section{Sample size and sampling procedure}

The representative sample size of participants was estimated using Kish Leslie formula $\mathrm{Z}^{2} \mathrm{P}(1-\mathrm{P}) / \delta^{2}$, considering $4.5 \%$ prevalence (P) of invasive NTS Salmonella infection in Tanga, Tanzania [12], standard normal deviation (Z) of 1.96 at $95 \%$ confidence and 3\% margin of error $(\delta)$. The sample size was estimated to be 301 with the inclusion of $10 \%$ non-respondent.

Eligible patients were obtained through a systematic random sampling procedure. The first participant of each day was randomly sampled from the first three patients with gastroenteritis. The subsequent participants were enrolled by skipping one. The expected number of patients with clinical features of gastroenteritis per day was around30, and the minimum of participants expected to be enrolled per day was 15 . This sampling procedure was performed on daily basis.

\section{Questionnaire survey and specimen collection}

A structured questionnaire was used to gather information on socio-demographic characteristics (sex, age, marital status, residence, occupation, level of education), clinical presentations (e.g fever, abdominal pain, headache, diarrhea, joint pain, body malaise, nausea and cough), and factors that increase the risk of Salmonella transmission (source of water, eating place, type of food, history of illness, water treatment, hygiene practices and domestic animals keeping). Patients or guardians were clearly instructed and illustrated on the amount and how to collect stool samples into a clean leak-proof container. After collection, unpreserved specimens were transported to the laboratory for processing within two hours.

\section{Laboratory procedures}

Isolation and identification of Salmonella species were conducted according to the Global Foodborne Infections Network laboratory protocol [13] and summarized in Fig. 1. About 1-2 g of stool sample was first inoculated into Selenite-F broth (HiMedia Laboratories Ltd., India) and incubated aerobically at $37^{\circ} \mathrm{C}$ for $18-24 \mathrm{~h}$. Thereafter, the samples from Selenite F broth was streaked on Xylose lysine deoxycholate agar (Oxoid Ltd., UK) and incubated aerobically at $37^{\circ} \mathrm{C}$ for $18-24 \mathrm{~h}$.

The clear to light pink colonies with distinct black spots at the center were considered as Salmonella 


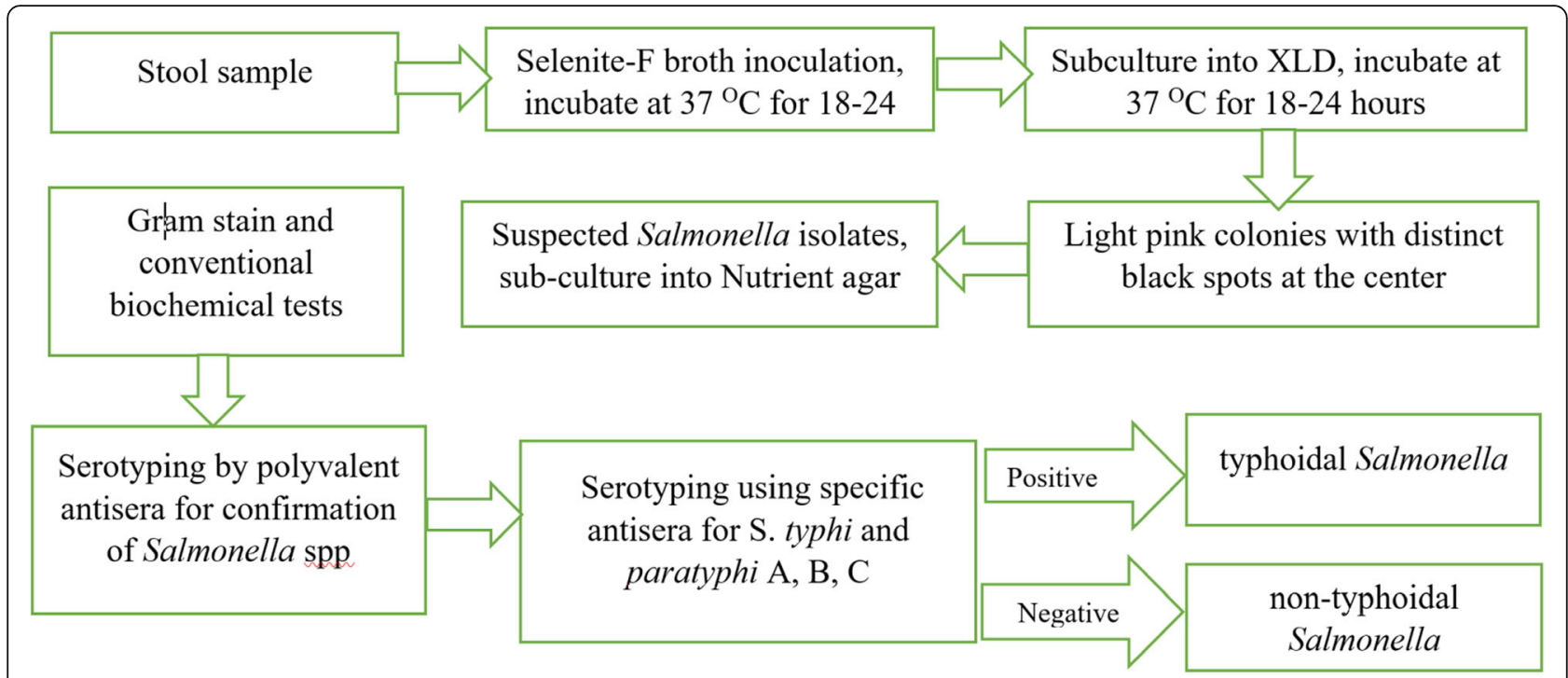

Fig. 1 Workflow of laboratory procedure for diagnosis of Salmonella spp

isolates. Suspected colonies were sub-cultured into Nutrient agar (Oxoid Ltd., UK) to get enough pure colonies for further identification. Preliminary identification was based on Gram stain reaction and conventional biochemical tests including triple sugar iron and sulfide indole motility tests (Oxoid Ltd., UK). Identified Salmonella spp. were confirmed by using agglutination reaction to polyvalent antisera (Denka Seiken, Tokyo Japan). Serotyping was performed by using specific antisera for S. typhi and paratyphi A, B, C (Biocan diagnostic, Canada), a nonreactive salmonella spp. were considered NTS (Fig. 1).

Antimicrobial susceptibility testing (AST) was performed using Kirby-Bauer's disc diffusion method [14]. Briefly, standard inoculums were prepared by direct colony suspension in normal saline, compared with 0.5 McFarland turbidity standards and inoculated on Muller-Hinton agar (Oxoid, UK). The plates with a maximum of six disks were incubated at $35 \pm 2{ }^{\circ} \mathrm{C}$ for $16-18$ $\mathrm{h}$ at the inverted position. The results were interpreted according to Clinical and Laboratory Standards Institute guidelines [14]. Escherichia coli ATCC 25922 was used as a reference organism for quality control. The antibiotic disks included for AST were: ceftriaxone $(30 \mu \mathrm{g})$, ciprofloxacin $(5 \mu \mathrm{g})$, chloramphenicol $(30 \mu \mathrm{g})$, ampicillin $(10 \mu \mathrm{g})$ and trimethoprim-sulphamethoxazole (1.25/ $23.75 \mu \mathrm{g}$ ) (Oxoid Ltd., UK). Selected antibiotic disks for AST were commonly used in our setting for the treatment of salmonellosis.

\section{Data management and analysis}

Statistical Package for Social Sciences version 20 was used for all data analyses. Descriptive analysis for categorical variables was summarized in the form of frequencies and percentages, while continuous variables were summarized as mean \pm Standard deviation. Sociodemographic characteristics, clinical presentations, factors that increase the risk of Salmonella transmission were independent variables while salmonella infection was dependent variable. The prevalence of Salmonella infection was calculated as proportion of positive stool culture among all cultures and expressed in percentages. Comparisons between the groups were done using ChiSquare test.

The Univariate logistic regression analysis was conducted to estimate the factors associated with Salmonella infection. The crude odds ratio (cOR) of each independent variable was determined. Variables with $p$-value $\leq 0.2$ in univariate analysis were considered in multivariable logistic regression analysis to examine the associations between the Salmonella infection and independent variables after adjustment for other variables. Associations in the multivariable logistic models were presented as adjusted odds ratio (AOR) estimated at $95 \%$ confidence intervals. Interaction between independent variables were examined and the Wald test was used to test the associations of the variables. The Hosmer-Lemeshow test was used to examine the overall fitness of the model. The level of significance was specified at 0.05 .

\section{Results}

Socio-demographic characteristics of study participants A total of 297 participants were enrolled in the study, the majority, 173 (58.2\%) were female. The mean age of participants was 26.7 years \pm 16.3 standard deviation. Age group 20 to 44 years 148 (49.8\%) had the most respondents. Participants with primary education (40.1\%) 
constituted the majority as well as unemployed (39.7\%) and single marital status (52.9\%). (Table 1 ).

\section{Clinical presentation of study participants}

Most participants presented with a history of abdominal pain $(77.8 \%)$, followed by headache $(59.6 \%)$ and fever (48.8\%). Only 99 (33.7\%) presented with Diarrhoea (Fig. 2).

\section{Prevalence of Salmonella infection}

Out of 297 stool cultures, 49 (16.5, 95\% CI: 12.7-21.1) were positive for Salmonella, of which 41 (83.7, 95\% CI: 70.9-91.5) were NTS, while eight $(16.3,95 \%$ CI: $8.5-$ 29.0) were Typhoid Salmonella species. Among the typhoid species, five were Salmonella typhi and three were Salmonella paratyphi. There was no significant difference in the proportion of Salmonella infection between females (19.1, 95\% CI: 13.9-25.6) and males (12.9, 95\% CI: 8.1-19.9). The lowest prevalence of Salmonella infection (8.3\%) was observed in children between 1 and 12 years, while the prevalence was almost similar ranging from 16 to $19 \%$ in age groups above 12 years. Employed participants had the highest proportion of Salmonella infection (30.0, 95\% CI: 19.1-43-7) compared to other

Table 1 Socio-demographic characteristics of study participants

\begin{tabular}{|c|c|c|}
\hline Variables & Frequency & Percentage (\%) \\
\hline \multicolumn{3}{|l|}{ Sex } \\
\hline Male & 124 & 41.8 \\
\hline Female & 173 & 58.2 \\
\hline \multicolumn{3}{|l|}{ Age group (years) } \\
\hline $1-12$ & 48 & 16.2 \\
\hline $13-19$ & 58 & 19.5 \\
\hline $20-44$ & 148 & 49.8 \\
\hline$\geq 45$ & 43 & 14.5 \\
\hline \multicolumn{3}{|l|}{ Occupation } \\
\hline Business & 29 & 9.8 \\
\hline Employed & 50 & 16.8 \\
\hline Farming & 100 & 33.7 \\
\hline None & 118 & 39.7 \\
\hline \multicolumn{3}{|l|}{ Level of education } \\
\hline None & 27 & 9.1 \\
\hline Primary Education & 119 & 40.1 \\
\hline Secondary & 91 & 30.6 \\
\hline Higher Education & 60 & 20.2 \\
\hline \multicolumn{3}{|l|}{ Marital status } \\
\hline Divorced & 2 & 0.7 \\
\hline Married & 132 & 44.4 \\
\hline Single & 157 & 52.9 \\
\hline Widowed/widower & 6 & 2.0 \\
\hline
\end{tabular}

occupations (13.7 95\% CI: 10.0-18.7) (Table 2). There was no significant difference in proportion of Salmonella isolation rate among participants with formal education (16.3, 95\% CI 12.4-21.2) and informal education (18.5, 95\% CI 8.2-36.7) as well as among married participants (18.9, 95\% CI: 13.2-26.5) and unmarried (14.5, 95\% CI 10.0-20.7) (Table 2).

Salmonella infection was more prevalent in patients presenting with abdominal pain (20.3, 95\% CI: 15.7-26.0 vs. $3.0,95 \% \mathrm{CI}, 0.8-10.4, p<0.05)$ and diarrhea $(25.3$, 95\% CI: $17.7-34.6$ vs. $12.1,95 \%$ CI: $8.3-17.4)$. There was no significant difference in the proportion of Salmonella infection between participants with and without fever, joint pain and headache (Table 2).

Patients using water from wells or rivers had a higher proportion of Salmonella infection (24.4, 95\% CI: 16.734.2) than those using tape water (13.0, 95\% CI: 9.1-18.3), $p<0.05$. Salmonella infection was more prevalent in the sampled individuals with preference of drinking untreated water (22.2, 95\% CI: $16.4-29.2$ vs. $10.1,95 \%$ CI: $6.1-16.2$, $p=0.005)$ and eating at restaurants $(27.9$ 95\% CI: 16.8 42.7 vs. $14.6,95 \% \mathrm{CI}: 10.8-19.4, p=0.029$ ). There was no significant difference in proportion of Salmonella infection with or without eating stewed beef, drinking raw milk, keep animals at home, hands washing in basin and preference of salad (Table 3).

\section{Antimicrobial susceptibility pattern}

Antimicrobial susceptibility was performed on 36 out of 49 (73.5\%) isolates. Amongst the isolate assessed for antimicrobial susceptibility, $8(100 \%$,) and $28(68.3 \%)$ were typhoid Salmonella and NTS respectively. ST All isolates were sensitive to ceftriaxone and ciprofloxacin. Resistance to ampicillin, tetracycline, co-trimoxazole and chloramphenicol were 100, 75.0, 27.8 and $16.7 \%$ respectively. Resistance were observed more in typhoid Salmonella species than NTS for tetracycline ( $88 \%$ vs $71 \%)$ and co-trimoxazole ( $100 \%$ vs $7 \%$ ). Out of 36 isolates, 9 (25\%) were multidrug resistance (MDR) being resistant to 3 or more groups of antibiotics (Table 4).

\section{Factors associated with Salmonella infection}

The odds of having Salmonella infection was eight times among patients reported abdominal pain (AOR 8.5, 95\% CI, 1.81-39.78) as compared to patients without abdominal pain. Having diarrhea had two times odds of having Salmonella infection (AOR 2.2, 95\% CI 1.13-4.24) compared to patients without diarrhea. The odd of having Salmonella infection were three times among employed participants (AOR 3.03, 95\% CI 1.42-6.49) than other occupations. (Table 5).

The odd of having Salmonella infection was three times more among participants regularly eating at restaurants (AOR 3.4, 95\% CI 1.28-8.93). Participants who 


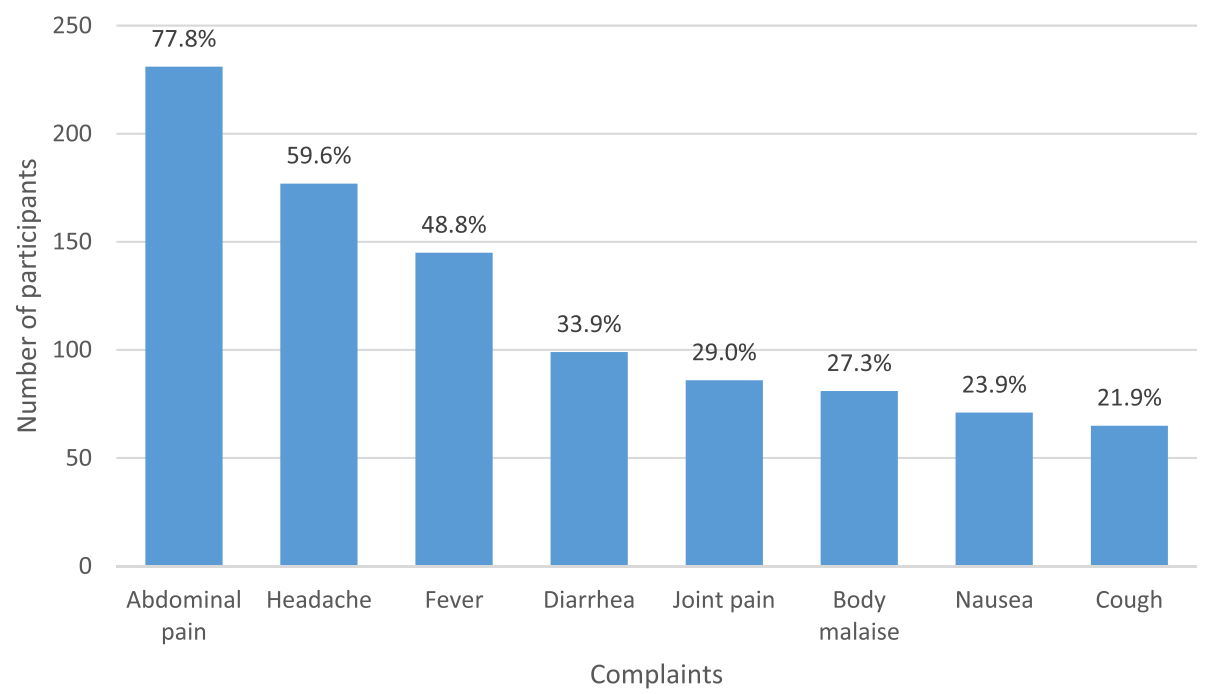

Fig. 2 Clinical presentations of participants enrolled in the study. The percentages of participants with each complaint are indicated at the top of the bars

reported using water from rivers or well had two times probability of Salmonella infection compared to those using tape water (AOR 2.02, 95\% CI 1.05-3.88), whereas drinking untreated water had three times higher chances of having Salmonella infection compared to those who drink treated water (AOR 2.6, 95\% CI 1.21-5.48) (Table 5). There were no potential interactions between wells/river source of water and drink untreated water as well as employment and eating at restaurant on Salmonella infection HIV status was checked, the interaction term was not significant. The Hosmer-Lemeshow test result was $p=0.52$ which indicated the fitness of the overall model.

\section{Discussion}

The current study has observed a considerable high prevalence of Salmonella infection among patients with gastrointestinal complaints. Some factors with significant contribution to Salmonella infections among people reporting gastrointestinal symptoms attending regional hospital in the Njombe region were identified. Study participants who reported regular eating at restaurants, use of water from the river or well and drinking untreated water had two to three times risk of having a Salmonella infection. This study has also demonstrated that Salmonella infection was found more among participants with employment, such that among enrolled individuals, employed had nearly four times more likelihood of Salmonella infection than non-employed.

The study found abdominal pain and diarrhea being the clinical determinants of Salmonella infection. Although abdominal pain, headache, and fever were the most predominant clinical symptoms similar to reports from other studies $[3,15]$, headache and fever had an insignificant association with the detection of Salmonella in stool culture. The findings of this study is comparable to reports from Kenya [4] and Ethiopia [5] where diarrhea was associated with salmonellosis.

The prevalence of Salmonella infection obtained in this study was higher than the findings from some studies in Africa reporting on Salmonella infection [4, 5, 9]. On the other hand, our finding was lower than the study conducted in Kenya [6]. The variation between studies on Salmonella infection could be due to differences in the type of patients enrolled such as age, immune status or underlying conditions, predisposing factors, as well as variations in bacteriological techniques and specimen used. In some studies, like the present one, only stool culture was performed, while other studies performed blood and stool cultures. For example, the study in Ethiopia [5] included all patients presenting with diarrhea while our study considered those attending clinician suspected gastroenteritis.

The prevalence of Salmonella infections varies from region to region depending on social-economic status, water sanitation, and hygiene practices $[12,16]$. The availability of clean and safe water has been a key determinant of the prevalence of Salmonella infection [6]. Therefore, the variations in different regions for clean, safe and scarcity of water could explain the variations in magnitude and contributing factors for Salmonella infection. The study found that drinking untreated water particularly from rivers or wells among people with gastrointestinal complaints had a high likelihood of being infected with Salmonella. The possible reason is that the river and/or wells are more likely to be contaminated with stool as a result of open defecation or by sharing with animals.

The present study observed the increased risk of Salmonella infection among employed people, who 
Table 2 Proportion of Salmonella infection among participants with socio-demographic characteristics and clinical presentations

\begin{tabular}{|c|c|c|c|c|}
\hline Variables & Total & $\begin{array}{l}\text { Number of } \\
\text { Positive }\end{array}$ & $\begin{array}{l}\text { Proportion positive } \\
(95 \% \mathrm{Cl})\end{array}$ & $P$-value \\
\hline Overall & 297 & 49 & $16.5(12.7-21.1)$ & \\
\hline \multicolumn{5}{|l|}{ Sex } \\
\hline Male & 124 & 16 & $12.9(8.1-19.9)$ & \multirow[t]{2}{*}{0.158} \\
\hline Female & 173 & 33 & $19.1(13.9-25.6)$ & \\
\hline \multicolumn{5}{|c|}{ Age group (years) } \\
\hline $1-12$ & 48 & 4 & $8.3(3.3-19.5)$ & \multirow[t]{4}{*}{0.615} \\
\hline $13-19$ & 58 & 10 & $17.2(9.6-28.9)$ & \\
\hline $20-44$ & 148 & 28 & $18.9(13.4-26.0)$ & \\
\hline$\geq 45$ & 43 & 7 & $16.3(8.1-30.0)$ & \\
\hline \multicolumn{5}{|l|}{ Occupation } \\
\hline Employed & 50 & 15 & $30.0(19.1-43.7)$ & \multirow[t]{2}{*}{0.005} \\
\hline Others & 247 & 34 & $13.8(10.0-18.7)$ & \\
\hline \multicolumn{5}{|l|}{ Education } \\
\hline Informal & 27 & 5 & $18.5(8.2-36,7)$ & \multirow[t]{2}{*}{0.767} \\
\hline Formal & 270 & 44 & $16.3(12.4-21.2)$ & \\
\hline \multicolumn{5}{|l|}{ Marital status } \\
\hline Married & 132 & 25 & $18.9(13.2-26.5)$ & \multirow[t]{2}{*}{0.311} \\
\hline Unmarried & 165 & 24 & $14.5(10.0-20.7)$ & \\
\hline \multicolumn{5}{|c|}{ Abdominal Pain } \\
\hline Yes & 231 & 47 & $20.3(15.7-26.0)$ & \multirow[t]{2}{*}{0.001} \\
\hline No & 66 & 2 & $3.0(0.8-10.4)$ & \\
\hline \multicolumn{5}{|l|}{ Fever } \\
\hline Yes & 145 & 26 & $17.9(12.5-25.0)$ & \multirow[t]{2}{*}{0.516} \\
\hline No & 152 & 23 & $15.1(10.3-21.7)$ & \\
\hline \multicolumn{5}{|l|}{ Headache } \\
\hline Yes & 177 & 27 & $15.3(10.7-21.3)$ & \multirow[t]{2}{*}{0.483} \\
\hline No & 120 & 22 & $18.3(12.4-26.2)$ & \\
\hline \multicolumn{5}{|l|}{ Diarrhea } \\
\hline Yes & 99 & 25 & 25. $3(17.7-34.6)$ & \multirow[t]{2}{*}{0.004} \\
\hline No & 198 & 24 & $12.1(8.3-17.4)$ & \\
\hline \multicolumn{5}{|l|}{ Joint pain } \\
\hline Yes & 86 & 20 & $23.3(15.6-33.2)$ & \multirow[t]{2}{*}{0.06} \\
\hline No & 211 & 29 & 13.7 (9.7-19.0) & \\
\hline
\end{tabular}

reported gastrointestinal complaints than unemployed. We speculate people with employment frequently eat at restaurants during working hours which increased the risk of infection. The association of Salmonella infection with eating in restaurant is an indication that some restaurants do not observe proper hygienic conditions for food preparation and storage, hence increasing the likelihood of Salmonella infection [3, 6].
Table 3 Proportion of Salmonella infection with participants' behavior and practices

\begin{tabular}{|c|c|c|c|c|c|}
\hline Variable & Total & $\begin{array}{l}\text { Number of } \\
\text { Positive }\end{array}$ & $\begin{array}{l}\text { Prevalence } \\
(\%)\end{array}$ & $(95 \% \mathrm{Cl})$ & $P$-value \\
\hline \multicolumn{6}{|l|}{ Source of water } \\
\hline Wells/River & 90 & 22 & 24.4 & $16.7-34.2$ & \multirow[t]{2}{*}{0.015} \\
\hline Tape water & 207 & 27 & 13.0 & $9.1-18.3$ & \\
\hline \multicolumn{6}{|c|}{ Drink untreated water } \\
\hline No & 158 & 35 & 22.2 & $16.4-29.2$ & \multirow[t]{2}{*}{0.005} \\
\hline Yes & 139 & 14 & 10.1 & $6.1-16.2$ & \\
\hline \multicolumn{6}{|l|}{ keep animal } \\
\hline Yes & 131 & 23 & 17.6 & $12.0-24.9$ & \multirow[t]{2}{*}{0.679} \\
\hline No & 164 & 26 & 15.9 & $11.1-22.2$ & \\
\hline \multicolumn{6}{|l|}{ Eat at restaurants } \\
\hline Yes & 43 & 12 & 27.9 & $16.8-42.7$ & \multirow[t]{2}{*}{0.029} \\
\hline No & 254 & 37 & 14.6 & $10.8-19.4$ & \\
\hline \multicolumn{6}{|c|}{ Hand wash practice } \\
\hline On the Basin & 115 & 23 & 20.0 & $13.7-28.2$ & \multirow[t]{2}{*}{0.196} \\
\hline Running water & 182 & 26 & 14.3 & $9.9-20.1$ & \\
\hline \multicolumn{6}{|l|}{ Eat salad } \\
\hline Yes & 133 & 18 & 13.5 & $8.7-20.4$ & \multirow[t]{2}{*}{0.215} \\
\hline No & 164 & 31 & 18.9 & 13.6-25.6 & \\
\hline \multicolumn{6}{|l|}{ Eat stewed beef } \\
\hline Yes & 67 & 13 & 19.4 & $11.7-30.4$ & \multirow[t]{2}{*}{0.467} \\
\hline No & 230 & 36 & 15.7 & $11.5-20.9$ & \\
\hline \multicolumn{6}{|l|}{ Drink raw milk } \\
\hline Yes & 5 & 2 & 40.0 & $11.7-76,9$ & \multirow[t]{2}{*}{0.153} \\
\hline No & 292 & 47 & 16.1 & $12.3-20.7$ & \\
\hline
\end{tabular}

The study found all Salmonella isolates sensitive to ceftriaxone and ciprofloxacin comparable to a study conducted in Kenya [17]. It should be noted that resistance of Salmonella spp. to fluoroquinolones has been reported in Uganda and Japan $[18,19]$. Sadly, high level of resistance towards ampicillin (100\%) and tetracycline (75.0\%); moderate

Table 4 Antimicrobial susceptibility pattern of Salmonella isolates from participants with gastrointestinal complaints $(N=36)$

\begin{tabular}{llll}
\hline $\begin{array}{l}\text { Name of } \\
\text { Antimicrobial }\end{array}$ & $\begin{array}{l}\text { Susceptible } \\
\text { isolates } \\
N(\%)\end{array}$ & $\begin{array}{l}\text { Intermediate } \\
\text { resistance isolates } \\
N(\%)\end{array}$ & $\begin{array}{l}\text { Resistant } \\
\text { isolates } \\
N(\%)\end{array}$ \\
\hline Ceftriaxone & $36(100.0)$ & $0(0.0)$ & $0(0.0)$ \\
Ciprofloxacin & $36(100.0)$ & $0(0.0)$ & $0(0.0)$ \\
Chloramphenicol & $28(77.8)$ & $2(5.6)$ & $6(16.7)$ \\
Co-trimoxazole & $25(69.4)$ & $1(2.8)$ & $10(27.8)$ \\
Tetracycline & $7(19.4)$ & $2(5.6)$ & $27(75.0)$ \\
Ampicillin & $0(0.0)$ & $0(0.0)$ & $36(100.0)$ \\
MDR & & & $9(25.0)$ \\
\hline
\end{tabular}


Table 5 Association of Salmonella infection with socio-demographic characteristics, clinical symptoms, and behavioral factors among participants with gastrointestinal complaints

\begin{tabular}{|c|c|c|c|c|}
\hline Variables & COR $(95 \% \mathrm{Cl})$ & $p$-value & AOR $(95 \% \mathrm{Cl})$ & $p$-value \\
\hline Male (Ref: Female) & $0.6(0.33-1.20)$ & 0.158 & $0.5(0.23-1.09)$ & 0.083 \\
\hline Employed (Ref: Unemployed) & $2.7(1.33-5.43)$ & 0.005 & $3.03(1.42-6.49)$ & 0.004 \\
\hline Abdominal Pain & $8.2(1.93-34.62)$ & 0.001 & $8.5(1.81-39.78)$ & 0.007 \\
\hline Diarrhea & $2.5(1.31-4.57)$ & 0.004 & $2.19(1.13-4.24)$ & 0.020 \\
\hline Joint pain & $1.9(1.01-3.59)$ & 0.045 & $1.8(0.97-3.77)$ & 0.060 \\
\hline Wells/River Source of water (Ref: Tape water) & $2.2(1.15-4.04)$ & 0.015 & $2.02(1.05-3.88)$ & 0.035 \\
\hline Drink untreated water & $2.5(1.30-4.95)$ & 0.005 & $2.6(1.21-5.48)$ & 0.014 \\
\hline Eat at restaurant & $2.3(1.07-4.82)$ & 0.029 & $3.4(1.28-8.93)$ & 0.032 \\
\hline Wash hand in basin (Ref: Running water) & $1.5(0.81-2.78)$ & 0.196 & $1.3(0.60-2.61)$ & 0.545 \\
\hline
\end{tabular}

Key: AOR Adjusted odds ratio, Cl Confidence interval, COR Crude odds ratio, Ref Reference

resistance to co-trimoxazole (27.8\%) and chloramphenicol (16.7\%) were observed. The findings are in accord with to the study done in Kenya [4] with some difference to ampicillin (27.9\%). The emergence of multidrug-resistant (MDR) among Salmonella spp. has been reported in some African countries such as Kenya [4] and Ethiopia [5]. The current study also demonstrated the presence of MDR Salmonella spp. considering the level of resistance to ampicillin, tetracycline, co-trimoxazole, and chloramphenicol. The high level of resistance could be attributed partly by the irrational use of antibiotics in our settings as previously reported $[6,20]$. In general, these results call for continuous monitoring of antimicrobials stewardship.

Blood culture is also considered the most suitable diagnostic method for Salmonella infection especially typhoid fever [3]. However, the technique is very expensive, requiring a well-equipped laboratory and not readily available in many health facilities in developing countries. One of the limitation of this study was that blood culture was not performed. This might have affected the isolation of typhoid Salmonella spp. thus underestimate the overall prevalence of Salmonellosis in this study. Due to limited resource, this study only differentiated typhoid and NTS without performing specific serotyping for NTS. The study is hospital based among sick suspected cases hence the findings could not be inferred to the general population.

\section{Conclusions}

There is a high prevalence of Salmonella infection among people who report gastrointestinal complaints and it is clinically predicated by diarhoea and abdominal pain. Employed participants and those eating at restaurant and drinking unsafe water had higher risk of infection. Our finding call for health management teams to ensure continued public health education on hygienic practices. There is a need for regular antimicrobial testing to control and prevent salmonellosis with multidrugresistant Salmonella spp.

\section{Abbreviations}

AOR: Adjusted odds ratio; AST: Antimicrobial susceptibility testing; $\mathrm{Cl}$ : Confidence interval; COR: Crude odds ratio; MDR: Multidrug-resistant; NTS: Non-typhoidal Salmonella,

\section{Acknowledgments}

The authors are grateful to Njombe Regional Hospital Management and Staff for their cooperation. Our sincere gratitude goes to patients for accepting to participate in this study and appreciation to research assistants for their tireless support throughout data collection.

\section{Authors' contributions}

FAN, AMA, MMM, MVM, contributed to designing the study, data collection, interpretation, and analysis. AJ, SFR played a part in data analysis and interpretation. FAN, drafted the manuscript. AJ, SFR, MVM participated in critically revising the manuscript. All authors read and approved the final manuscript

\section{Funding}

This study received financial support from Tanzania Field Epidemiology and Laboratory Training Programme for data collection and laboratory work. The funder had no role in the design of the study and collection, analysis, interpretation of data and writing the manuscript.

\section{Availability of data and materials}

The datasets used during the current study are available from the corresponding author on a reasonable request.

\section{Ethics approval and consent to participate}

The ethical approval for the study was obtained from the Senate Research and Publication Committee, the Institutional Review Board of Muhimbili University of Health and Allied Sciences (MUHAS). Permission to conduct the study was obtained from Region Health Management and Hospital Management. Written informed consent was obtained from each participant/guardian before enrolment. The identification number was employed and only authorized personnel had access to data.

\section{Consent for publication}

Not applicable.

\section{Competing interests}

The authors declare that they have no competing interests.

\section{Author details}

${ }^{1}$ Muhimbili University of Health and Allied Sciences, Dar es Salaam, Tanzania.

${ }^{2}$ Field Epidemiology and Laboratory Training Programme, Dar es Salaam,

Tanzania. ${ }^{3}$ National Institute for Medical Research, Dar es Salaam, Tanzania. 
Received: 2 August 2019 Accepted: 6 February 2020

Published online: 12 February 2020

\section{References}

1. Crump JA, Luby SP, Mintz ED. The global burden of typhoid fever. Bull World Health Organ. 2004;82(5):346-53.

2. Majowicz SE, Musto J, Scallan E, Angulo FJ, Kirk M, O'Brien SJ, Jones TF, Fazil A, Hoekstra RM. The global burden of nontyphoidal Salmonella gastroenteritis. Clin Infect Dis. 2010;50(6):882-9.

3. Crump JA, Sjolund-Karlsson M, Gordon MA, Parry CM. Epidemiology, clinical presentation, laboratory diagnosis, antimicrobial resistance, and antimicrobial Management of Invasive Salmonella Infections. Clin Microbiol Rev. 2015;28(4):901-37.

4. Muthumbi E, Morpeth SC, Ooko M, Mwanzu A, Mwarumba S, Mturi N, Etyang AO, Berkley JA, Williams TN, Kariuki S, et al. Invasive Salmonellosis in Kilifi, Kenya. Clin Infect Dis. 2015;61(Suppl 4):S290-301.

5. Equale T, Gebreyes WA, Asrat D, Alemayehu H, Gunn JS, Engidawork E. Non-typhoidal Salmonella serotypes, antimicrobial resistance and $\mathrm{CO}^{-}$ infection with parasites among patients with diarrhea and other gastrointestinal complaints in Addis Ababa, Ethiopia. BMC Infect Dis. 2015;15:497

6. Galgallo DA, Roka ZG, Boru WG, Abill K, Ransom J. Investigation of a typhoid fever epidemic in Moyale Sub-County, Kenya, 2014-2015. J Health Popul Nutr. 2018;37(1):14

7. Mogasale V, Maskery B, Ochiai RL, Lee JS, Mogasale W, Ramani E, Kim YE, Park JK, Wierzba TF. Burden of typhoid fever in low-income and middleincome countries: a systematic, literature-based update with risk-factor adjustment. Lancet Glob Health. 2014;2(10):e570-80.

8. Chipwaza B, Mhamphi GG, Ngatunga SD, Selemani M, Amuri M, Mugasa JP, Gwakisa PS. Prevalence of bacterial febrile illnesses in children in Kilosa district, Tanzania. PLoS Negl Trop Dis. 2015:9(5):e0003750.

9. Mtove G, Amos B, von Seidlein L, Hendriksen I, Mwambuli A, Kimera J, Mallahiyo R, Kim DR, Ochiai RL, Clemens JD, et al. Invasive salmonellosis among children admitted to a rural Tanzanian hospital and a comparison with previous studies. PLoS One. 2010;5(2):e9244.

10. Khan MI, Soofi SB, Ochiai RL, Khan MJ, Sahito SM, Habib MA, Puri MK, Von Seidlein L, Park JK, You YA et al: Epidemiology, clinical presentation, and patterns of drug resistance of Salmonella Typhi in Karachi, Pakistan $J$ Infect Dev Ctries 2012, 6(10):704-714

11. Moyo SJ, Gro N, Matee MI, Kitundu J, Myrmel H, Mylvaganam H, Maselle SY, Langeland N. Age specific aetiological agents of diarrhoea in hospitalized children aged less than five years in Dar Es Salaam, Tanzania. BMC Pediatr. 2011:11:19.

12. Biggs HM, Lester R, Nadjm B, Mtove G, Todd JE, Kinabo GD, Philemon R, Amos B, Morrissey AB, Reyburn $H$, et al. Invasive Salmonella infections in areas of high and low malaria transmission intensity in Tanzania. Clin Infect Dis. 2014;58(5):638-47.

13. Word Health Organization: Isolation of Salmonella and Shigella from faecal specimens. WHO Global Foodborne Infections Network. 2010. (2011).

14. Wayne P: Performance standards for antimicrobial susceptibility testing: twenty fifth international supplement M100-S25. Clinical and Laboratory Standards Institute. In.; 2015.

15. Antillon M, Warren JL, Crawford FW, Weinberger DM, Kurum E, Pak GD, Marks F, Pitzer VE. The burden of typhoid fever in low- and middle-income countries: a meta-regression approach. PLoS Negl Trop Dis. 2017;11(2): e0005376.

16. Crump JA, Heyderman RS. A perspective on invasive Salmonella disease in Africa. Clin Infect Dis. 2015;61(Suppl 4):S235-40.

17. Kariuki S, Revathi G, Muyodi J, Mwituria J, Munyalo A, Mirza S, Hart CA Characterization of multidrug-resistant typhoid outbreaks in Kenya. J Clin Microbiol. 2004;42(4):1477-82

18. Kobayashi T, Hayakawa K, Mawatari M, Mezaki K, Takeshita N, Kutsuna S, Fujiya Y, Kanagawa S, Ohmagari N, Kato Y, et al. Case report: failure under azithromycin treatment in a case of bacteremia due to Salmonella enterica Paratyphi a. BMC Infect Dis. 2014;14:404

19. Ota S, Maki Y, Mori K, Hamamoto T, Kurokawa A, Ishihara M, Yamamoto T, Imai K, Misawa K, Yuki A, et al. Diagnosis of imported Ugandan typhoid fever based on local outbreak information: a case report. J Infect Chemother. 2016;22(11):770-3.
20. Horumpende $\mathrm{PG}$, Said SH, Mazuguni FS, Antony ML, Kumburu HH, Sonda TB, Mwanziva CE, Mshana SE, Mmbaga BT, Kajeguka DC, et al. Prevalence, determinants and knowledge of antibacterial selfmedication: a cross sectional study in North-Eastern Tanzania. PLoS One. 2018;13(10):e0206623.

\section{Publisher's Note}

Springer Nature remains neutral with regard to jurisdictional claims in published maps and institutional affiliations.

\section{Ready to submit your research? Choose BMC and benefit from:}

- fast, convenient online submission

- thorough peer review by experienced researchers in your field

- rapid publication on acceptance

- support for research data, including large and complex data types

- gold Open Access which fosters wider collaboration and increased citations

- maximum visibility for your research: over $100 \mathrm{M}$ website views per year

At $\mathrm{BMC}$, research is always in progress.

Learn more biomedcentral.com/submissions 